\title{
Educación literaria y construcción de identidades: hacia el empoderamiento y la igualdad ${ }^{1}$
}

Patricia Martínez León

Doctora en Didáctica de la Lengua y la Literatura

Universitat de València https://orcid.org/0000-0002-7269-5505

Patricia.Martinez-Leon@uv.es

\section{Resumen}

La historia de la humanidad y la actualidad informativa muestran las dramáticas consecuencias de la construcción negativa de una diferencia representada por dos alteridades fundamentales: la del otro cultural y la de la otra de género, sobre las que se ha ejercido una persistente violencia simbólica y física. En este artículo exploramos cómo se construyen, inferiorizan y subordinan estas dos alteridades, y cómo pueden ser deconstruidas, posicionadas en un plano de igualdad o empoderadas desde la educación literaria. La relevancia de lo anterior radica en las múltiples formas de desigualdad persistentes tanto en materia cultural como de género, que nos proponemos contrarrestar desde el ámbito de la educación literaria y en sintonía con los estudios interculturales o con la crítica feminista desde los estudios literarios.

Palabras clave: Educación literaria; identidad; igualdad; interculturalidad; feminismo.

\section{Literary education and identity construction - empowering the oppressed and social equality}

\section{Hbstract}

Human history and news bulletins show the dramatic consequences of the negative construction of two fundamental othernesses: cultural and gender. Persistent symbolic and physical violence have been built on each. We explore how these two othernesses are constructed and subordinated - and how literary education can deconstruct these perceptions, create equality and empower. This is important because of the many forms of persistent cultural and gender

\footnotetext{
1 Procedencia del artículo: El contenido de este artículo forma parte de la tesis doctoral de la autora, titulada "La construcción de identidades a través de la educación literaria en Educación Secundaria".
} 
inequality. We propose counteracting this inequality using literary education in line with intercultural studies or feminist criticism from literary studies.

Keywords: Equality; feminism; identity; interculturality; literary education.

Recibido: 16 de septiembre del 2020. Aprobado: 09 de noviembre del 2020 Artículo de reflexión https://doi.org/10.25100/poligramas.v0i52.10967

¿Cómo citar este artículo en MLH? - How to quote this article in MLA?

Martínez León, Patricia. "Educación literaria y construcción de identidades: hacia el empoderamiento y la igualdad" Poligramas 52 (2021): e.2010967. Web. Fecha de acceso

(día, mes en mayúscula y abreviado, y año).

\section{Hsimetrías de poder en la construcción de identidades}

Parece innegable que somos herederos de una historia marcada por la legitimación de unas identidades y el sometimiento de otras, y la invención de categorías identitarias jerarquizadas, en tanto mecanismo de control social, vinculado a la expansión imperialista, los modelos políticos colonialistas y el sistema capitalista y patriarcal. Estas formas de dominación (capitalista, patriarcal, etnocéntrica) se relacionan aumentando la vulnerabilidad de los más débiles e implican, a menudo, proyectos de vida que oprimen y excluyen a diferentes alteridades.

Por otra parte, las políticas de globalización neoliberal (definida por Said como el sistema por el cual una reducida élite financiera amplía su poder al mundo entero, inflando los precios de las materias primas y de los servicios, y redistribuyendo la riqueza desde los sectores de menor renta hacia los de mayor renta) generan desigualdades y desplazamientos, y el nuevo orden internacional alimenta nacionalismos y fundamentalismos que, en su respuesta de resistencia al dominio y a la homogeneización, a su vez, agudizan en muchos casos la subordinación de género (Arroyabe; Azcona; lacono; Nash; Puigvert; Salazar Benítez; Said).

Esas formas de dominación tienen que ver, en gran parte, con el poder de construir las definiciones sociales, tal y como apunta Cobo: 
Todo sistema de dominación para serlo y para reproducir su hegemonía debe tener la fuerza y el poder suficiente para producir las definiciones sociales. En otros términos, los sistemas de dominación lo son porque los dominadores poseen el poder de la heterodesignación de los dominados, el de la autodesignación sobre sí mismos y el de la designación sobre las realidades prácticas y simbólicas sobre las que se asienta su dominio (Globalización 50-51).

Al hilo de la relación entre la opresión de género y la cultural, que son las dos formas en las que nos centraremos, se expresa también Cobo del siguiente modo:

La dominación masculina suele ser convertida por los varones en la piedra de toque de su cultura, por lo que identifica la esencia de su cultura con sus propios privilegios. De modo que el control y la propiedad de las mujeres por parte de los varones se convierte en uno de los elementos centrales a proteger en las comunidades culturales que se sienten inferiorizadas y sometidas a procesos de cambio social. Lo que en el fondo no es otra cosa que defender el contrato sexual por el que los varones originalmente pactaron a las mujeres como propiedad masculina y como subordinadas sexuales. Parecería que los varones están resignados a admitir ciertos cambios culturales, pero se aferran "como a un clavo ardiendo" al contrato sexual, pues este pacto les convierte en colectivo dominante sobre sus mujeres. Así, aunque pierdan poder como cultura siguen conservándolo como genérico masculino. El multiculturalismo más radical y más patriarcal aspira a que una de las esencias culturales a proteger sea precisamente la subordinación de las mujeres (Ellas y nosotras 14).

Pero para comprender cómo se originan las asimetrías de poder y las desigualdades sociales asociadas a los procesos de construcción de identidades, hemos de detenernos en la noción de diferencia y atender, en particular, a cómo esta puede ser entendida y organizada.

Construida en términos esencialistas y concebida como negativa e inferior, esto es, estableciendo fronteras fijas entre grupos opuestos que se presentan como esencialmente distintos, la diferencia dará lugar a grupos herméticos jerarquizados y, consiguientemente, a la opresión y a la desigualdad. Concebida, por el contrario, en términos relacionales, como contingente y variable, y no como algo esencial, permitirá aunar diversidad, igualdad y democracia. En este sentido, la diferencia, en función del contexto, también puede ser 
organizada jerárquicamente para legitimar la dominación, u horizontalmente, a modo de protesta ante la opresión (Brah).

Como anticipábamos, las formas de opresión a que da lugar esa construcción negativa de la diferencia no son independientes, sino que se relacionan, por lo que conviene cuestionarlas y desmontarlas conjuntamente. De hecho, el paralelismo entre el discurso racista colonial y el discurso sexista es ostensible: ambos traducen diferencias étnicas o sexuales en categorías socioculturales jerarquizadas en términos de superioridad/inferioridad.

Advertidas las desigualdades de poder asociadas a determinados procesos de construcción identitaria, merecen ser referidos aquí algunos planteamientos teóricos bastante afines: la visión aportada por Appiah en su taxonomía de la opresión, que alude a categorías identitarias que habrían funcionado como instrumento de subordinación y constreñimiento de la autonomía de los seres humanos; la propuesta presentada por Castells, quien diferencia tres modalidades u orígenes de construcción identitaria (identidades legitimadora y de resistencia, de una parte, vinculadas a los ejercicios de dominación y resistencia a la opresión de diferentes actores sociales, e identidad proyecto, de otra, orientada a la transformación de la estructura social); la perspectiva de De Lucas, que se refiere a la imposición de una uniformidad que conlleva el sacrificio de otras identidades y a la desigual integración en la distribución de poder y riqueza de los distintos grupos sociales; la lectura de Bartolomé Ruiz, basada en la prescripción de comportamientos y prácticas a través de dispositivos de control de las instituciones que intervienen en el universo simbólico de los individuos; o la teoría de Sen, quien repara en la propensión a la violencia y el enfrentamiento que adquiere la relación entre la asimetría de poder y el mundo de identidades divididas a que esta conduce.

\section{De la violencia simbólica a la violencia física: un camino que desandar}

La colonización discursiva se establece como una forma de violencia simbólica, consistente en la asimetría de poder y el reparto desigual del lenguaje en el encuentro discursivo con el otro. Por medio de una serie de técnicas discursivas, se impone la supuesta superioridad de un "nosotros» convertido en referente normativo y se define y subordina a los "otros», deshumanizados e inferiorizados para justificar su domesticación, la negación de la palabra y 
de protagonismo en las narrativas y la eliminación de su tradición literaria y cultural (CastroKlaren; González Abrisketa y Mendiola; Mezzadra; Mezzadra y Rahola; Quispe-Agnoli; Spivak; Talpade; Zevallos).

Más allá de lo anterior, el carácter de muchos conflictos contemporáneos ha sido relacionado con la ausencia de reconocimiento o el reconocimiento inadecuado de determinadas identidades, heridas en el plano simbólico. Bello apunta, en este sentido, que un adecuado reconocimiento de las identidades humilladas, y la sustitución de una ética de la apropiación y exclusión del otro por una ética de no apropiación e inclusión, podrían sentar las bases de un futuro más pacífico en lo concerniente a las relaciones entre distintas identidades culturales.

El magistral análisis de Maalouf (El desajuste del mundo) ilumina, en este punto, el carácter identitario de las divisiones asociadas a gran parte de esos conflictos contemporáneos, y extiende la magnitud de las asimetrías de poder y el posicionamiento de autoridad de las potencias occidentales (encabezadas por Estados Unidos) a una dimensión planetaria.

Tales conflictos se originarían sobre un escenario marcado por la desfavorable relación gestada entre dominantes y dominados durante la época colonial, y por las humillaciones que hirieron unas identidades construidas, en términos de negatividad, como la alteridad de Occidente (en la actualidad sentidas como amenazadas por la homogeneización asociada a la mundialización) y cuyo resentimiento redundaría en un potencial de violencia, en los peores casos, materializado.

En otra obra y otros términos, el mismo autor se refiere, en relación con esto, a una suerte de tensiones identitarias con desviaciones criminales, asociadas a identidades culturales (cuyo fundamental sostén serían las lenguas) oprimidas, marginadas y, consiguientemente, agredidas, que motivarían respuestas violentas en una guerra alimentada entre dominados y dominadores (Maalouf, Identidades asesinas).

Asimismo, vincula esas tensiones, las oposiciones binarias y las prácticas de dominación entre identidades, a la peligrosa conceptualización que las reduce a una sola pertenencia y a la incapacidad de empatía que alimenta la visión de los otros como amenaza, confiriendo una justificación aparente para su eliminación.

En el contexto delineado, y ante la desaparición de lenguas, literaturas y comunidades, se encontraría el reto de gestionar la diversidad humana, cultural y lingüística, frente al que 
Maalouf (El desajuste del mundo) propone superar el desconocimiento o conocimiento superficial (que deformarían peligrosamente nuestra interpretación de los conflictos actuales) de los otros culturales, a través de la acogida de sus literaturas desde el espacio educativo, identificado como espacio privilegiado para la dignificación, el reconocimiento y la inclusión de esa alteridad reiteradamente humillada.

En palabras del citado autor:

Si tenemos empeño en proteger la paz civil, si deseamos que la diversidad humana se traduzca en una coexistencia armoniosa y no en tensiones que generen violencia, no podemos permitirnos ya conocer a los demás de forma aproximativa, superficial y burda. Necesitamos conocerlos de modo sutil, de cerca, y hasta diría que en su intimidad. Y eso solo puede conseguirse mediante su cultura. Y, de entrada, mediante su literatura (Maalouf, El desajuste del mundo 207-208).

Naïr es otro autor imprescindible en el análisis de la dimensión identitaria de los conflictos contemporáneos. Por una parte, establece un paralelismo entre los procesos de colonización en el siglo XIX y el imperialismo y las políticas neocoloniales americanas actuales, en las que operan las armas del mercado imponiendo unas determinadas políticas económicas a los países del Sur y la manipulación a través de los medios y la industria cultural que domina el imaginario de los receptores. Por otra, sostiene que las nuevas formas de dominación se apoyan en una concepción esencialista de las culturas, que traduce la diferencia en el mensaje del choque de identidades irreconciliables, utilizado para movilizar las emociones y culturalizar las relaciones sociales, económicas y políticas, haciendo ver que los vínculos y conflictos entre los pueblos son definidos por las pertenencias originarias de estos y ocultando de este modo otros factores e intereses, y, en definitiva, cómo están dispuestos los hilos de las relaciones de fuerza y dominación.

Otros autores insisten también en que las asimetrías de poder propias del colonialismo persisten en la actualidad en el plano cultural y económico en forma de imposición de valores, comportamientos, modelos de identidad, deuda externa, creciente desigualdad en las relaciones comerciales, consumo excesivo de unos países y situación de dependencia y empobrecimiento a la que se condena a otros como resultado de la globalización, lo que habría dado lugar a una suerte de colonia internacional (Demenchonok; Fernandes; Fornet-Betancourt; Rao). 
En definitiva, a través de la construcción del otro como diferencia negativa (terrorista, inintegrable, etc.), se legitiman tanto su anulación simbólica como múltiples modalidades de violencia física (de género, racista, colonialista, etc.) (Bello; Nicolás).

Así, por ejemplo, la construcción del otro de género (la otra) como amenaza a una identidad masculina deteriorada, conduciría a la violencia de género. O el orientalismo reproducido en el presente mediante la construcción y difusión de una imagen negativa de árabes y musulmanes, articulada alrededor de una idea de amenaza e invasión, se emplearía como justificación de la fortificación de fronteras, el rearme, las agresiones y la ocupación de territorios (Bello; Nicolás). En esta línea, tal y como apunta Said, se habrían realizado estudios equiparables sobre la mentalidad islámica, el carácter del árabe, la mentalidad de los negros o la personalidad de los judíos.

Desactivar esta violencia exigiría la deconstrucción de la diferencia negativa y la construcción del otro como diferencia positiva. Veamos cómo es posible contribuir a ese propósito, en particular, desde la educación literaria.

\section{El literario: espacio de igualdad, resistencia y liberación}

El literario ha sido destacado como un espacio privilegiado para fomentar la justicia e igualdad sociales, el reconocimiento e inclusión de los excluidos, la comprensión de los marginados u oprimidos, o la superación de prejuicios, estereotipos culturales o construcciones negativas de la diferencia, mediante la representación de una diversidad de identidades (así como de las historias, desigualdades, padecimientos y luchas que las acompañan), la incorporación de voces silenciadas en el canon y la pluralización de los personajes retratados en las obras que lo conforman, o por medio de una recepción crítica (Nussbaum, El cultivo de la humanidad).

La práctica de la lectura literaria, como es sabido, a menudo supone una apertura de las coordenadas espaciotemporales y de la perspectiva cultural del lector, que le brinda la oportunidad de aproximarse a diferentes realidades, favoreciendo un mayor respeto, conocimiento y comprensión de la diversidad. En este sentido, se plantea el concepto de imaginación narrativa o empática, entendida como "la capacidad de pensar cómo sería estar en el lugar de otra persona, de interpretar con inteligencia el relato de esa persona y de entender los sentimientos, los deseos y las expectativas que podría tener esa persona" (Nussbaum, Sin fines de lucro 132). 
Esta identificación individual que permite la lectura literaria supone con frecuencia empatizar con el dolor, las discriminaciones e injusticias padecidas por otros; es importante en la medida en que puede contribuir a superar el odio y los estereotipos construidos alrededor de colectivos homogeneizados en el imaginario del receptor, y a sustituir así la actitud de sospecha y el sentimiento de amenaza por un mayor conocimiento y una comprensión empática. Con ello, en el mejor de los casos, se pueden prevenir episodios de desigualdad, violencia o dominación entre identidades culturales.

Al hilo de lo expuesto, en palabras de Nussbaum:

El odio y la opresión colectiva a menudo nacen de la incapacidad para individualizar. El racismo, el sexismo y muchas otras formas de prejuicio pernicioso se basan con frecuencia en la atribución de características negativas a todo un grupo ... El retrato deshumanizador es insostenible ... cuando uno logra extender al individuo la actitud literaria de la imaginación compasiva ... La comprensión literaria ... promueve hábitos mentales que conducen a la igualdad social en la medida en que contribuyen al desmantelamiento de los estereotipos en que se basa el odio colectivo ... es muy valioso extender esta comprensión literaria buscando experiencias literarias donde nos identifiquemos compasivamente con miembros individuales de grupos marginados $u$ oprimidos de nuestra sociedad, aprendiendo por un tiempo a ver el mundo a través de sus ojos y reflexionando (Justicia poética 130-131).

En suma, la literatura y la imaginación desarrollada por el lector durante la lectura permitirían trascender el miedo, la desconfianza o el odio al otro, así como su estigmatización y deshumanización, para, alcanzados un mayor conocimiento y una mayor comprensión desde la identificación empática, avanzar desde el rechazo y la violencia hacia el entendimiento y la convivencia deseables.

No obstante, autoras como Scarry nos alertan de que hemos de ser cautelosos con la confianza que depositamos en el concepto de imaginación literaria. Acepta que nuestra capacidad de imaginar o representarnos literariamente a los otros de manera compleja incide en la forma en que actuamos y se ve favorecida por la literatura, pero destaca las limitaciones de la imaginación literaria para resolver los problemas que a menudo acompañan a la relación 
con la alteridad y el peligro de depositar responsabilidades que conciernen a la legalidad en el terreno de lo literario. En los siguientes términos, la autora expresa:

Ahora mismo, por ejemplo, la política nuclear de los Estados Unidos permite que un presidente, actuando prácticamente solo, autorice el lanzamiento de armas nucleares. ¿De qué manera podría el pueblo de los Estados Unidos proteger a otros pueblos del súbito empleo de este monárquico sistema armamentístico? ¿Deberíamos confiar en que en el momento del lanzamiento el presidente tuviera repentinamente la capacidad de imaginar a otro pueblo en toda su magnitud, con todas sus profundas preocupaciones; de imaginar no sólo una caricatura de dirigente, sino a los hombres y a las mujeres, a la juventud de ese país? (139-140).

Más allá de lo anterior, no podemos obviar, en este punto, la persistencia de prácticas coloniales, relaciones de desigualdad y dependencia en el presente, que han sido acogidas bajo el término neocolonialismo.

Un posible ejemplo de retorno del relato colonial podría ser, en este sentido, la acometida desde los países unificados en Europa (antiguos colonizadores) contra la inmigración «ilegal» de personas del tercer mundo, mediante la fortificación de fronteras (Mezzadra y Rahola; Shohat).

En el terreno que más directamente nos concierne, podemos citar la desaparición de lenguas, la relegación de determinadas literaturas en el escenario neoimperial o las representaciones estereotipadas de ciertos "otros» convertidos en objeto de consumo por la industria cultural actual (Castro-Klaren; Quispe-Agnoli).

En esta línea, los estudios poscoloniales (y otros como los transatlánticos, los interculturales o los de subalternidad) hacen una lectura crítica de las relaciones coloniales y neocoloniales. Subyace a estos un propósito de comprensión crítica de nuestro tiempo y de las nuevas expresiones de prácticas colonialistas e imperiales, de explotación y de dominio. Dichos estudios cuestionan la constitución eurocéntrica del canon literario y defienden la heterogeneidad constitutiva del relato histórico (acogiendo una diversidad de voces), la representación de identidades subordinadas y la iluminación de episodios de dominación y violencia, resistencia y liberación (Mezzadra; Mezzadra y Rahola; Ortega; Shohat; Spivak). 


\section{El otro cultural y la otra de género}

Como avanzábamos, la crudeza de determinados episodios de incomprensión y violencia nos obliga a detenernos en la construcción y deconstrucción, en tanto diferencia negativa, de las alteridades cultural y de género. Será nuestro propósito explorar cómo es posible contribuir a su empoderamiento y liberación desde la educación literaria.

Por su lucidez y claridad expositiva, no podíamos dejar de encabezar los dos subapartados que componen este punto con las siguientes palabras de Amin Maalouf:

Para cualquier sociedad, y para el conjunto de la humanidad, el trato a las minorías no es un asunto entre otros muchos; es, junto con el trato a las mujeres, uno de los datos más reveladores de progreso ético o de retroceso. Un mundo en el que se respete cada día algo más la diversidad humana, en donde todas las personas puedan expresarse en la lengua que prefieran, profesar en paz sus credos y asumir tranquilamente sus orígenes sin exponerse a la hostilidad y al desprestigio ni de las autoridades ni de la población, este es un mundo que está avanzando, que progresa, que remonta el vuelo. A la inversa, cuando prevalecen las situaciones crispadas en lo referente a las identidades, como sucede en la actualidad en la gran mayoría de los países, tanto en el norte del planeta como en el sur, cuando nos resulta cada día un poco más difícil poder ser tranquilamente quienes somos y usar nuestra lengua o practicar nuestra fe en libertad, ¿cómo no hablar de retroceso? (El desajuste del mundo 72).

\section{Construcción y deconstrucción del otro cultural}

Las descripciones o caracterizaciones de la alteridad cultural (en ocasiones arbitrarias, restringidas y estereotipadas) realizadas en el texto literario poseen implicaciones que trascienden el plano del discurso, en tanto que inciden en las representaciones que el receptor, a su vez, conforma de esa alteridad en su imaginario individual, e, indirectamente, en las acciones que emprenderá contra o con esos otros (Sanz Cabrerizo; Schwab).

Al respecto de esas descripciones o caracterizaciones, uno de los enfoques de la perspectiva intercultural, adoptada desde la didáctica de las lenguas y literaturas, habría centrado su atención precisamente en la superación de las representaciones distorsionadas, reduccionistas y estereotipadas del otro, mediante la selección consciente de obras (en una 
diversidad de formatos) cuya recepción ofrecería al alumnado imágenes de la alteridad más positivas y adecuadas a la realidad (Puren).

No cabe duda de que la literatura se presta de una manera especial a la transgresión de fronteras entre identidades culturales y a la exploración de la pluralidad de pertenencias que en este trabajo defendemos. Reconocido, además, el desarrollo de la imaginación "ética» activada en el encuentro literario del lector con la alteridad cultural, parece evidente que pueda desempeñar algún papel ante las relaciones positivas que desearíamos que se entablasen entre culturas. Y es en esta línea que se habría derivado un creciente (y razonable) interés por el estudio de la representación literaria del otro y del encuentro cultural, de los contactos entre culturas y literaturas, e incluso de la figura del profesor de esta área, en tanto mediador cultural (Millington; Sanz Cabrerizo; Schwab).

Efectivamente, la investigación en nuestra didáctica específica respalda la idea de que las representaciones de los encuentros culturales en el plano literario pueden contribuir a la movilidad y a las relaciones culturales reales, mediante la flexibilización de las fronteras entre identidades culturales, atravesadas en el imaginario del receptor (Schwab).

A este respecto, la denominada «literatura de minorías» desempeñaría un papel esencial, tal como expone Schwab en las líneas que reproducimos a continuación:

Mientras la literatura de minorías ... siga haciendo hincapié en la heterogeneidad de los encuentros culturales y de las mezclas culturales en sociedades multiculturales cada vez más globalizadas, esta literatura formará parte de los complejos procesos de negociación de nuevas fronteras culturales, así como de su necesaria transgresión. En el campo de intermediación cultural de la literatura, se simulan encuentros culturales al modo del imaginario, los cuales después repercuten por su parte en la política de la representación y de la comunicación cultural (246-247).

Otro ejercicio de apertura al otro cultural, tan valioso como necesario en los procesos de construcción identitaria que suscitan nuestro interés, puede hallarlo el lector adolescente en la experiencia intercultural posibilitada, en particular, por la literatura de viajes, por la literatura que aborda el tema de las adopciones interculturales o por la literatura de autores fronterizos, cuyos sentimientos de pertenencia son plurales y, a menudo, contradictorios. Por medio de esta el lector trasciende las coordenadas en las que se halla inscrito e, incluso, toma consciencia de la 
arbitrariedad de las fronteras, en una inestimable ocasión para superar la construcción negativa de la diferencia, así como los prejuicios y estereotipos asociados a la alteridad, y para reparar en las potencialidades de la gestación de una identidad cultural plural (Ibarra y Ballester).

Aguilar (¿Somos racistas?) se centra, en particular, en la representación de la alteridad en los textos e ilustraciones de la Literatura Infantil y Juvenil (en adelante, LIJ), toda vez que esta redundaría en la formación de identidades de género, etnia o clase, y resolvería la conveniencia de un corpus que promueva la toma de conciencia y el compromiso social. De una parte, huyendo de una narrativa mercantil y utilitaria, que estrecharía el espacio a la imaginación y el pensamiento del lector, y pondría en riesgo la heterogeneidad cultural e ideológica. Y, de otra, optando por obras que incluyan las voces de una alteridad silenciada y visibilicen comunidades minoritarias (sin supeditarlas a la perspectiva dominante), que pueden retratar la resistencia y la solidaridad de personajes oprimidos y explotados, y que procuren un mayor conocimiento de la diversidad (desde una aproximación empática y crítica), o ayuden a profundizar en la comprensión de los mecanismos de discriminación, injusticia y desigualdad persistentes, así como en algunas de las barbaries históricas que a estos se asocian.

A modo de conclusión, podríamos decir que reconocer el trazado de fronteras entre identidades culturales y la construcción negativa de la diferencia como obra humana (en otras palabras, desnaturalizarlas) supone la apertura de un espacio para el empoderamiento de los oprimidos y la igualdad social desde la educación literaria, en la medida en que nos revela la reversibilidad de las situaciones dadas.

Puede ser oportuno recapitular algunas de las medidas u orientaciones que podrían favorecer esta posibilidad.

a) Una de ellas pasaría por la traducción de la heterogeneidad cultural de nuestras sociedades a la de los personajes literarios representados en las obras seleccionadas, en las cuales pudiesen obtener reflejo, asimismo, sus historias, tradiciones y algunas de las formas de opresión y desigualdad padecidas, revirtiendo ello de manera positiva en el conocimiento de la diversidad humana y en la conciencia histórica del receptor.

b) Otra opción podría hallarse en la modificación de las representaciones literarias del otro cultural que lo estereotipan, cosifican e inferiorizan, redundando en la proliferación de discursos discriminatorios, actitudes y prácticas en la misma dirección, que requieren ser atajados desde el sustrato cultural que las sustenta (que es también literario). 
c) Por descontado, una vía inexcusable consistiría en la inclusión de las voces creativas de la alteridad cultural en los cánones literarios, cuestionados los criterios subyacentes a su constitución y las exclusiones históricas realizadas y valorizando las identidades culturales inferiorizadas, a través de un componente nuclear como son sus literaturas. En este sentido, la selección del corpus de obras trabajadas en las aulas habría de partir de un ejercicio crítico, reflexionado y socialmente comprometido de los docentes.

d) Y también podrían contemplarse apuestas literarias especialmente favorables a la reflexión alrededor del encuentro intercultural, a la aproximación empática al otro, o a la pluralización y la apertura identitarias, tales como la literatura de viajes, migraciones o adopciones, o la producción creativa de autores fronterizos o diaspóricos. En definitiva, obras que inviten a la flexibilización de las fronteras entre identidades culturales, en conformidad con una visión superadora de los discursos esencialistas y de esa conceptualización hermética, tan peligrosa, de las identidades.

\section{Construcción y deconstrucción de la otra de género}

Pese a las innegables conquistas en materia de igualdad de género, no podemos pasar por alto los retrocesos en el terreno de los derechos de las mujeres en contextos de crisis, la actual contradicción entre valores y prácticas a la que se ha hecho referencia en términos de esquizofrenia social, la sobrecarga de responsabilidad que a menudo asumen las mujeres o el aumento de la violencia machista.

Podemos considerar como constantes el trabajo peor pagado o no remunerado de las mujeres, una tasa de analfabetismo que en la actualidad duplica a la de los hombres, las diversas formas de explotación que sufren las mujeres o el hecho de que solo un $1 \%$ de la propiedad mundial nos pertenezca. Otra constante destacable es el carácter transcultural de la subordinación de género (Mernissi diría que el harén occidental es la talla 38) e, incluso, la conversión de los privilegios masculinos y la sujeción de las mujeres es un elemento de la identidad cultural que se presenta como innegociable, especialmente cuando esta se ve amenazada. Por otra parte, se ha insistido en que el poder y el paradigma de logro (ese atreverse, gustarse, crecerse, empoderarse) se sitúan todavía como asignaturas pendientes de las mujeres. 
La interiorización de relaciones de dominación a través de la socialización, el mito del amor romántico, el código patriarcal en las relaciones amorosas o la división sexual del trabajo podrían considerarse formas de dominación persistentes, a las que se suman otras como una sociedad hipersexualizada, la adicional exigencia estética impuesta a las mujeres profesionales o la sustitución del anterior modelo del varón como proveedor económico, según el cual se ha denominado a la mujer como proveedora frustrada (por la jornada interminable y el aumento del trabajo gratuito e invisible) (Aguilar, Lectura; Amorós; Cobo, Globalización; De la Concha, Introducción; García de León).

La preocupación se agudiza tras acceder a los resultados de estudios relativamente recientes que analizan el discurso de adolescentes y evidencian una interiorización, por parte de chicos y chicas, de modelos, valores y roles de género tradicionales, y una adhesión acrítica a las prescripciones dominantes. Además, dichos estudios muestran la pervivencia de posiciones relacionales desiguales y asimétricas entre los géneros -lo que genera estructuras y mecanismos de desigualdad desapercibidos, como consecuencia de la inmersión en el sistema

y los discursos de género dominantes-, e, incluso, dan cuenta de cierta legitimación de la dominación masculina y de la violencia sobre las mujeres en el discurso de los chicos. Pese a lo anterior, se detecta la conformación identitaria de los adolescentes a través de discursos contradictorios, que revelan, al mismo tiempo, la insostenibilidad y la pervivencia de los modelos de masculinidad y feminidad tradicionales, y que defienden y afirman la igualdad entre los sexos, evidenciando, a la vez, persistentes desigualdades (Amigot et al.; Martínez Benlloch et al.).

Ante la situación descrita, el papel de la alfabetización y del acceso al mundo cultural en la emancipación y la conquista de autonomía por parte de esta alteridad femenina históricamente construida ha sido y es incontestable, convirtiéndose la lectura y la escritura en prácticas liberadoras y empoderadoras, en la lucha contra la subordinación y la desigualdad padecidas (Aguilar, Lectura; Bollmann; Showalter; Tusquets).

\section{El sustrato cultural y literario de las identidades y la violencia de género}

Una definición bastante esclarecedora es la que presenta el género sencillamente como construcción sociocultural de la diferencia sexual. Se trata, en este sentido, de prescripciones 
(en cuanto a actitudes, valores, expectativas) que establecen lo propio de hombres y mujeres, y que, en tanto se presentan como naturales, constriñen las decisiones y los proyectos vitales de las personas (Butler; Conway, Bourque y Scott; Lamas, Introducción).

El género como categoría analítica posee una gran relevancia porque nos ayuda a entender cómo la diferencia estructura nuestra percepción y se transforma en desigualdad en la organización de la vida social y en el control de recursos, a explicar la subordinación de las mujeres y, en definitiva, a desactivar mecanismos de discriminación (Lamas, La antropología feminista; Usos, dificultades y posibilidades).

En palabras de Cabré:

es en los años 70 cuando se plantea la diferencia entre el sexo (como categoría biológica) y el género (como categoría social). El concepto de género como construcción cultural pasó pues a convertirse en el nudo gordiano de un conflicto arrastrado desde hace siglos: el de la mujer supeditada al hombre en respuesta a su supuesta inferioridad. Si esa mujer "inferior" era una construcción, alguien tenía que ser el responsable de su "inferioridad" (177).

La construcción social de la diferencia sexual se realiza a través de representaciones que instalan una serie de características, pautas de conducta y valores presentados como normativos. Cuando esa diferencia construida entre las categorías de género se naturaliza, se establece una jerarquía en torno a una oposición binaria, en términos de superioridad/inferioridad, entre hombres y mujeres, que ha convertido a las segundas en la alteridad inferiorizada, negándoles la condición de sujetos y justificando su subordinación (Nash, Diversidad).

Y bien, al hilo de esa construcción sociocultural del género, existe lo que podríamos denominar un sustrato simbólico e ideológico -en definitiva, cultural- de las identidades de género, en gran medida heredado, y que redunda en la conformación de tales identidades (incidiendo en el imaginario individual y colectivo). Este sustrato, que es también literario, a menudo, refuerza el orden patriarcal. Y lo hace por medio de una serie de mecanismos discursivos que revierten en el aprendizaje de un papel de subordinación y domesticidad por parte de las mujeres, alrededor de una noción de género que restringe los roles y opciones de estas, que las invisibiliza, las silencia y las excluye de la escena social (Aguilar, Lectura). 
El sustrato cultural al que nos referíamos, tejido por una densa red de discursos, y bajo la envoltura estética de lo artístico, también encubre y naturaliza la violencia de género, mediante la cosificación, estereotipación y desvalorización de la mujer en determinadas representaciones de la feminidad, y a través de alusiones implícitas o explícitas a agresiones que, de este modo, llegan a normalizarse.

Tal y como explica Cerezo:

El funcionamiento de este tipo de textos es el mismo que observamos en nuestra sociedad. Es decir, el subconsciente textual trabaja exactamente igual que el subconsciente social. Aunque en la superficie tanto textual como social parezca reinar, hasta cierto punto, la normalidad en cuanto a la relación entre los sexos, aunque se pretendan silenciar determinadas actitudes machistas, aunque a veces nos hagan creer, por un lado como lectores, y por otro como ciudadanos, que la historia "va de otra cosa", sin embargo, lo cierto es que tanto en los textos como en la realidad social existe, como estamos viendo, un sustrato textual y a la vez social que permanece siempre latente, que es muy difícil de exterminar y que adquiere autoridad a la hora de dar significado, en el caso de los textos, a las historias de violencia de género que nos cuentan, y, en el caso de la sociedad, a sus estructuras de comportamiento misógino (28-29).

Así, a través del canon y de símbolos, tópicos y mitos recurrentes, perviviría en el discurso artístico una mirada autoritaria masculina que define y caracteriza a una "otra» relegada a la condición de objeto pasivo (Cerezo; De la Concha, Introducción; Reyzábal).

Coincidimos con Cabré en que la cuestión del canon no es en absoluto insustancial, pues:

es el resultado de la necesidad de legitimar el poder y de justificar con ello la sumisión. Quienes hacen el canon son los guardianes de la cultura oficial y tienen mucho interés en que este perviva dentro de unas fronteras bien delimitadas ... Y si la subordinación de las mujeres ha sido un hecho cultural y no biológico, en justa correspondencia tendrá que ser cultural la reparación de esa subordinación (297-313).

Otro de los aspectos que no deberíamos dejar de considerar es la existencia de una oferta lectora y cultural discriminatoria, diferenciada en función del género, a la que se asocia una 
diferenciación de las preferencias de los propios adolescentes, de acuerdo con percepciones prejuiciosas en cuanto a temas destinados a uno u otro género (Díaz-Plaja).

En este sentido, se han identificado en el siglo XXI producciones sexistas (la denominada chick lit juvenil) dirigidas exclusivamente a chicas y escritas predominantemente también por mujeres, que redundan en una construcción reduccionista y discriminatoria de la identidad femenina (belleza, superficialidad, subordinación). En el caso de los chicos, paralelamente, aunque en menor medida (el repertorio de modelos ofrecidos sería más amplio en este caso), se trasladan roles machistas preferentemente a través de las representaciones o imágenes masculinas presentadas en las diversas pantallas (Olid).

Y la violencia simbólica que subordina a las mujeres en el plano del discurso (a través de determinadas construcciones de feminidad y la consiguiente atribución de roles), en el plano social sustentaría el orden patriarcal y también la violencia de género, vinculada a una identidad varonil resistente al abandono del aludido orden, resentida y amenazada por la progresiva conquista de poder por parte de las mujeres (De la Concha, En el umbral).

\section{Crítica feminista desde los estudios literarios}

Las estrechas representaciones de lo femenino en la literatura, que inciden en la socialización y conformación de las subjetividades y expectativas de las mujeres, son abordadas, desnaturalizadas y subvertidas desde la crítica feminista.

Showalter distingue dos modalidades dentro de la crítica feminista. La primera, revisionista, se basaría en el análisis, el cuestionamiento y la resignificación de las representaciones de la mujer en la literatura, mientras que la segunda se centraría en el estudio de la literatura escrita por mujeres y de su diferencia, así como en la relación de estas con la cultura literaria.

En esta línea, el fortuito encuentro entre deconstrucción y feminismo en el terreno de los estudios literarios permite interrogar la oposición jerárquica masculino/femenino, cuestionando los discursos que construyen el orden patriarcal para invertir la posición discursiva reservada a las mujeres. Así, se analizan los poderes implicados en la construcción discursiva para subvertir tal jerarquía, orientándose los mecanismos interpretativos a descubrir relaciones de opresión, significados de dominación masculina o rastros misóginos en mitos, temas y personajes (Catelli). 
En este punto, un frente de ineludible abordaje, tanto desde la crítica feminista como desde la educación literaria, es el del canon. Diversas autoras nos alumbran alrededor de las consecuencias de un canon literario androcéntrico, patriarcal y misógino, con escasa presencia de obras escritas por mujeres, así como de las responsabilidades que a este respecto se nos derivarían a los docentes.

En esta línea, exponen cómo un canon literario de tales características redunda en la universalización de la mirada masculina (desde la que, de este modo, se construyen los modelos sociales con que se verán confrontadas las mujeres), contribuye a normalizar la misoginia y supone, además, la ausencia de referentes femeninos de realización intelectual y artística.

Ello hace necesario el cuestionamiento del canon (interrogando las valoraciones ideológicas y de género subyacentes a su constitución), la superación de sus distorsiones sexistas y la incorporación de obras escritas por mujeres, asumida la dificultad de la tarea de rescatar obras de relevancia literaria de entre las anteriormente excluidas, de justificar su selección y de acceder a información acerca de tales obras y sus autoras.

A este respecto, nos adherimos a los fines que Reyzábal explicita en su propuesta de revisión del canon literario:

a) desenmascarar la idea implícita en el canon vigente de que la expresión literaria de la mujer ha sido minoritaria y marginal; b) redescubrir muchas voces femeninas silenciadas, dando la posibilidad de abrir el currículo escolar o universitario a nuevas propuestas de análisis que permitan reconsiderar (mediante la recuperación de textos ignorados hasta ahora) si se mantienen como referente los mismos hitos literarios o si, por el contrario, se sustituyen o amplían con otros en los que tenga cabida la voz femenina; c) alertar a las nuevas generaciones sobre los factores de discriminación existentes en la selección de modelos estéticos, fomentando así su capacidad crítica; d) animar a las mujeres de hoy a encontrar sus cauces expresivos propios, aportándoles modelos (vitales y estéticos) en femenino que les permitan construir su identidad de género y proyección estética al margen de tópicos interesadamente sesgados (22).

Como venimos sosteniendo, y a modo de conclusión, el ámbito educativo posee una gran relevancia en los procesos de construcción identitaria, en especial, en un tiempo vital decisivo como es la adolescencia. Pero los procesos educativos, como sabemos, no son neutrales, por 
lo que pueden contribuir, también en materia de género, a fines muy diversos, incluso contrapuestos, ya sea de manera implícita. Es por ello que consideramos que tiene sentido explicitar aquí cuál sería el fin del modelo coeducativo al que nos adherimos, siguiendo a Miyares: desarrollar actitudes, valores y capacidades que permitan la construcción de una identidad personal y social no condicionada por la ideología, las normas y los estereotipos sexuales, y desactivar en las aulas la identidad "ser mujer».

A la luz de lo hasta aquí sostenido, la educación literaria puede convertirse en un espacio privilegiado para enfrentar la desigualdad y a la violencia de género, abordándolas desde ese sustrato cultural que las sustenta. Destacamos, a continuación, tres posibles vías.

a) La primera se basaría en la transformación de las representaciones de lo femenino, acogiendo, además, en las nuevas imágenes otras diferencias (de clase, raza, etnia u orientación sexual). Esta vía puede ser abordada desde la reescritura de mitos y la deconstrucción de historias canónicas y discursos patriarcales, la renovación de metáforas de género y valores morales opresores, o las creaciones literarias alternativas (por ejemplo, cuentos feministas), superadoras de estereotipos sexistas.

b) Una segunda vía consistiría en la inclusión de voces de mujer y el protagonismo de figuras femeninas en las obras del corpus, que ilustren la victimización y el empoderamiento de las mujeres, y que permitan redefinir las identidades de género en el siglo XXI. En este punto, también podemos considerar un hito al respecto de la identidad y la agencia de la mujer, el hecho de comenzar a titular obras literarias con nombres femeninos.

c) La tercera vía la constituiría una recepción activa y crítica, que implique el posicionamiento del lector ante las representaciones de lo femenino en los textos literarios, advertida su repercusión en el afianzamiento o derribe de ideologías patriarcales conducentes a la violencia de género.

En definitiva, desde la educación literaria es posible denunciar y contribuir a superar roles estrechos, prejuicios y estereotipos, y, en consecuencia, el modelo patriarcal, la desigualdad y la violencia de género, redefiniendo las identidades de género mediante la transformación del imaginario colectivo, nutrido de ese sustrato literario y cultural al que nos hemos referido. 


\section{Referencias}

Aguilar, Consol. "Lectura, género, feminismo y LIJ". Lenguaje y Textos. 28. 2008: 113-128. Digital.

Aguilar, Consol. “¿Somos racistas? Sí. La lucha contra el miedo a lo desconocido y la LIJ”. CLIJ: Cuadernos de literatura infantil y juvenil. 172. 2011. 28-36. Digital.

Amigot, Patricia et al. "Identidades de género, relaciones afectivas y violencia: un análisis social del discurso adolescente". Imaginario cultural, construcción de identidades de género y violencia: formación para la igualdad en la adolescencia. Isabel Martínez Benlloch et al. Madrid: Instituto de la Mujer, 2008. 245-284. Impreso.

Amorós, Celia. Mujeres e imaginarios de la globalización: reflexiones para una agenda teórica global del feminismo. Rosario: Homo Sapiens, 2008. Impreso.

Appiah, Kwame Anthony. La ética de la identidad. Buenos Aires: Katz, 2007. Impreso.

Arroyabe, Estanislao. "Europa como mosaico de identidades: algunas reflexiones". Identidades culturales y minorías étnicas en Europa. David Turton y Julia González. Bilbao: Universidad de Deusto, 2001. 23-35. Impreso.

Azcona, Jesús. "Las barreras de las culturas identitarias: migración y límites sociales". Identidades culturales y derechos humanos. Coord. Manuel Calvo García. Madrid: Dykinson, 2002. 23-48. Impreso.

Bartolomé Ruiz, Carlos. "Identidades políticas y sujetos sociales. El espectro de nuevos autoritarismos". De identidades: reconocimiento y diferencia en la modernidad líquida. Coord. Raúl Susín Betrán y David San Martín Segura. Valencia: Tirant lo Blanch, 2008. 135-184. Impreso.

Bello, Gabriel. Postcolonialismo, emigración y alteridad. Granada: Comares, 2007. Impreso.

Bollmann, Stefan. "Las mujeres, que leen, son peligrosas. Una historia ilustrada de la lectura desde el siglo XIII hasta el siglo XXI". Las mujeres, que leen, son peligrosas. Stefan Bollmann. Madrid: Maeva, 2006. 20-37. Impreso.

Brah, Avtar. Cartografías de la diáspora: identidades en cuestión. Madrid: Traficantes de sueños, 2011. Impreso.

Butler, Judith. "Variaciones sobre sexo y género: Beauvoir, Wittig y Foucault". El género: la construcción cultural de la diferencia sexual. Comp. Marta Lamas. México: Bonilla Artigas, 2015. 291-312. Impreso. 
Cabré, Ma Ángeles. Leer y escribir en femenino. España: Aresta, 2013. Impreso.

Castells, Manuel. L'era de la informació. Economia, societat i cultura. El poder de la identitat. Volumen II. Barcelona: UOC, 2003. Impreso.

Castro-Klaren, Sara. "Estudios transatlánticos: geo-políticas en una perspectiva comparada". Estudios transatlánticos postcoloniales. I. Narrativas comando/sistemas mundos: colonialidad/modernidad. Ed. Ileana Rodríguez y Josebe Martínez. Barcelona: Anthropos, 2010. 91-120. Impreso.

Catelli, Nora. "Literatura y literariedad". Teoría literaria y literatura comparada. Jordi Llovet et al. Barcelona: Ariel, 2012. 31-83. Impreso.

Cerezo, Marta. "El canon literario y sus efectos en la construcción cultural de la violencia de género: los casos de Chaucer y Shakespeare". El sustrato cultural de la violencia de género: literatura, arte, cine y videojuegos. Coord. Ángeles De la Concha. Madrid: Síntesis, 2010. 19-44. Impreso.

Cobo, Rosa. "Globalización y nuevas servidumbres de las mujeres". Teoría feminista: de la Ilustración a la globalización. De los debates sobre el género al multiculturalismo. Ed. Celia Amorós y Ana de Miguel. Madrid: Minerva, 2005. 265-300. Impreso.

Cobo, Rosa. "Ellas y nosotras en el diálogo intercultural". Interculturalidad, feminismo y educación. Ed. Rosa Cobo. Madrid: Catarata, 2006. 11-33. Impreso.

Conway, Jill K., Susan C. Bourque y Joan W. Scott. "El concepto de género". El género: la construcción cultural de la diferencia sexual. Comp. Marta Lamas. México: Bonilla Artigas, 2015. 23-33. Impreso.

De la Concha, Ángeles. "Introducción". El sustrato cultural de la violencia de género: literatura, arte, cine y videojuegos. Coord. Ángeles De la Concha. Madrid: Síntesis, 2010. 7-18. Impreso.

De la Concha, Ángeles. "En el umbral de una nueva poética: cambios en la representación literaria de la violencia de género". El sustrato cultural de la violencia de género: literatura, arte, cine y videojuegos. Coord. Ángeles De la Concha. Madrid: Síntesis, 2010. 143-172. Impreso.

De Lucas, Javier. Globalización e identidades: claves políticas y jurídicas. Barcelona: Icaria, 2003. Impreso. 
Demenchonok, Edward. "Diálogo intercultural y las controversias de la globalización”. Culturas y poder. Interacción y asimetría entre las culturas en el contexto de la globalización. Ed. Raúl Fornet-Betancourt. Bilbao: Desclée de Brouwer, 2003. 81-107. Impreso.

Díaz-Plaja, Ana. "Entre libros: la construcción de un itinerario lector propio en la adolescencia". Lecturas adolescentes. Coord. Teresa Colomer. Barcelona: Graó, 2009. 119-150. Impreso.

Fernandes, W. "La globalización y la ética de una cultura única". Culturas y poder. Interacción y asimetría entre las culturas en el contexto de la globalización. Ed. Raúl FornetBetancourt. Bilbao: Desclée de Brouwer, 2003. 29-50. Impreso.

Fornet-Betancourt, Raúl. "Interacción y asimetría entre las culturas en el contexto de la globalización". Culturas y poder. Interacción y asimetría entre las culturas en el contexto de la globalización. Ed. Raúl Fornet-Betancourt. Bilbao: Desclée de Brouwer, 2003. 1527. Impreso.

García de León, María Antonia. Cabeza moderna/corazón patriarcal. Un diagnóstico social del género. Barcelona: Anthropos, 2011. Impreso.

González Abrisketa, Olatz, y Ignacio Mendiola. "Cuando el otro habla: entre el silenciamiento y la performatividad". Estudios transatlánticos postcoloniales. I. Narrativas comando/sistemas mundos: colonialidad/modernidad. Ed. Ileana Rodríguez y Josebe Martínez. Barcelona: Anthropos, 2010. 209-234. Impreso.

lacono, Alfonso M. "Raza, nación, pueblo: caras ocultas del universalismo". Identidades comunitarias y democracia. Ed. Héctor Claudio Silveira Gorski. Madrid: Trotta, 2000. 95111. Impreso.

Ibarra, Noelia y Josep Ballester. "La construcción de la identidad a través de la adopción intercultural en la literatura infantil y juvenil contemporánea". Diacrítica. 28, 3. 2014: 103-120. Digital.

Lamas, Marta. "Introducción”. El género: la construcción cultural de la diferencia sexual. Comp. Marta Lamas. México: Bonilla Artigas, 2015. 11-21. Impreso.

Lamas, Marta. "La antropología feminista y la categoría de género". El género: la construcción cultural de la diferencia sexual. Comp. Marta Lamas. México: Bonilla Artigas, 2015. 93122. Impreso. 
Lamas, Marta. "Usos, dificultades y posibilidades de la categoría de género". El género: la construcción cultural de la diferencia sexual. Comp. Marta Lamas. México: Bonilla Artigas, 2015. 313-348. Impreso.

Maalouf, Amin. El desajuste del mundo: cuando nuestras civilizaciones se agotan. Madrid: Alianza, 2009. Impreso.

Maalouf, Amin. Identidades asesinas. Madrid: Alianza, 2009. Impreso.

Martínez Benlloch, Isabel et al. "Conclusiones". Imaginario cultural, construcción de identidades de género y violencia: formación para la igualdad en la adolescencia. Isabel Martínez Benlloch et al. Madrid: Instituto de la Mujer, 2008. 287-299. Impreso.

Mezzadra, Sandro. "Introducción". Estudios postcoloniales: ensayos fundamentales. Comp. Sandro Mezzadra. Madrid: Traficantes de sueños, 2008. 15-31. Impreso.

Mezzadra, Sandro y Federico Rahola. "La condición postcolonial. Unas notas sobre la cualidad del tiempo histórico en el presente global". Estudios postcoloniales: ensayos fundamentales. Comp. Sandro Mezzadra. Madrid: Traficantes de sueños, 2008. 261278. Impreso.

Millington, Mark I. "La ubicación crítica en la lectura intercultural". Interculturas/Transliteraturas. Comp. Amelia Sanz Cabrerizo. Madrid: Arco, 2008. 133-162. Impreso.

Miyares, Alicia. "Multiculturalismo, coeducación y ciudadanía". Interculturalidad, feminismo y educación. Ed. Rosa Cobo. Madrid: Catarata, 2006. 34-54. Impreso.

Naïr, Sami. Diálogo de culturas e identidades. Madrid: Editorial Complutense, 2006. Impreso.

Nash, Mary. "Diversidad, multiculturalismos e identidades: perspectivas de género". Multiculturalismos y género: un estudio interdisciplinar. Ed. Mary Nash y Diana Marre. Barcelona: Bellaterra, 2001. 21-47. Impreso.

Nash, Mary. "Representaciones culturales y discurso de género, raza y clase en la construcción de la sociedad contemporánea". El desafí de la diferencia: representaciones culturales e identidades de género, raza y clase. Ed. Mary Nash y Diana Marre. Bilbao: Universidad del País Vasco, 2003. 21-35. Impreso.

Nicolás, Miquel. "Para una crítica de la multiculturalidad en la aldea planetaria: argumentos de síntesis y recursos bibliográficos". Multiculturalismo e identidades permeábeais na literatura infantil e xuvenil. Coord. Blanca Ana Roig, Isabel Soto y Pedro Lucas Domínguez. Vigo: Xerais, 2006. 13-48. Impreso. 
Nussbaum, Martha Craven. Justicia poética. La imaginación literaria y la vida pública. Barcelona: Andrés Bello, 1997. Impreso.

Nussbaum, Martha Craven. El cultivo de la humanidad. Una defensa clásica de la reforma en la educación liberal. Barcelona: Paidós Ibérica, 2005. Impreso.

Nussbaum, Martha Craven. Sin fines de lucro. Por qué la democracia necesita de las humanidades. Madrid: Katz, 2010. Impreso.

Olid, Isabel. "Entre chicos y chicas: la fuerza de los estereotipos. La nueva «chick lit» para adolescentes". Lecturas adolescentes. Coord. Teresa Colomer. Barcelona: Graó, 2009. 169-184. Impreso.

Ortega, Julio. "Post-teoría y estudios transatlánticos". Estudios transatlánticos postcoloniales. I. Narrativas comando/sistemas mundos: colonialidad/modernidad. Ed. Ileana Rodríguez y Josebe Martínez. Barcelona: Anthropos, 2010. 77-89. Impreso.

Puigvert, Lidia. "Igualdad de diferencias". Mujeres y transformaciones sociales. Elisabeth BeckGernsheim, Judith Butler y Lidia Puigvert. Barcelona: El Roure, 2001. 93-107. Impreso.

Puren, Christian. "Del enfoque comunicativo a la perspectiva de la acción y de lo intercultural a lo co-cultural". Interculturas/Transliteraturas. Comp. Amelia Sanz Cabrerizo. Madrid: Arco, 2008. 253-278. Impreso.

Quispe-Agnoli, Rocío. "Desvelando colonialidades: áreas en busca de atención en los estudios latinoamericanos". Estudios transatlánticos postcoloniales. 1. Narrativas comando/sistemas mundos: colonialidad/modernidad. Ed. Ileana Rodríguez y Josebe Martínez. Barcelona: Anthropos, 2010. 185-207. Impreso.

Rao, S. "Las perspectivas filosóficas de la asimetría cultural y los retos de la globalización". Culturas y poder. Interacción y asimetría entre las culturas en el contexto de la globalización. Ed. Raúl Fornet-Betancourt. Bilbao: Desclée de Brouwer, 2003. 51-59. Impreso.

Reyzábal, María Victoria. Canon literario y diferencia de género en la educación. Madrid: La Muralla, 2012. Impreso.

Said, Edward. Orientalismo. Barcelona: Debolsillo, 2014. Impreso.

Salazar Benítez, Octavio. Autonomía, género y diversidad. Itinerarios feministas para una democracia intercultural. Valencia: Tirant Humanidades, 2017. Impreso. 
Sanz Cabrerizo, Amelia. "Introducción". Interculturas/Transliteraturas. Comp. Amelia Sanz Cabrerizo. Madrid: Arco, 2008. 11-64. Impreso.

Scarry, Elaine. "La dificultad de imaginar otras gentes". Los límites del patriotismo. Identidad, pertenencia y ciudadanía mundial. Martha Craven Nussbaum. Barcelona: Paidós, 2013. 129-142. Impreso.

Schwab, G. "Restricción y movilidad. Hacia la dinámica del contacto cultural en la literatura". Interculturas/Transliteraturas. Comp. Amelia Sanz Cabrerizo. Madrid: Arco, 2008. 227251. Impreso.

Sen, Amartya. Identidad y violencia: la ilusión del destino. Madrid: Katz, 2007. Impreso.

Shohat, Ella. "Notas sobre lo postcolonial". Estudios postcoloniales: ensayos fundamentales. Comp. Sandro Mezzadra. Madrid: Traficantes de sueños, 2008. 103-120. Impreso.

Showalter, Elaine. "La crítica feminista en el desierto". Textos de teorías y crítica literarias: del formalismo a los estudios postcoloniales. Nara Araújo y Teresa Delgado. Barcelona: Anthropos, 2010. 381-404. Impreso.

Spivak, Gayatri Chakravorty. "Estudios de la subalternidad. Deconstruyendo la historiografía". Estudios postcoloniales: ensayos fundamentales. Comp. Sandro Mezzadra. Madrid: Traficantes de sueños, 2008. 33-67. Impreso.

Talpade, Chandra. "Bajo los ojos de Occidente. Saber académico y discursos coloniales". Estudios postcoloniales: ensayos fundamentales. Comp. Sandro Mezzadra. Madrid: Traficantes de sueños, 2008. 69-101. Impreso.

Tusquets, Esther. "¿Son peligrosas las mujeres que leen?". Las mujeres, que leen, son peligrosas. Stefan Bollmann. Madrid: Maeva, 2006. 10-19. Impreso.

Zevallos, Juan. "La introducción de los discursos colonial y postcolonial en los estudios latinoamericanos". Estudios transatlánticos postcoloniales. 1. Narrativas comando/sistemas mundos: colonialidad/modernidad. Ed. Ileana Rodríguez y Josebe Martínez. Barcelona: Anthropos, 2010. 161-181. Impreso. 